\title{
¡LUCHAR, ¡RESISTIR! VIOLACIONES AL DERECHO A LA VIVIENDA Y RESISTENCIA POPULAR EN LAS “FAVELAS” DE RÍO DE JANEIRO EN TIEMPOS DE MEGAEVENTOS
}

\author{
ANDRÉ ABREU / BEATRIZ REIS / MICHEL COUTO / RENATA SEADE / THIAGO \\ DAMAS / WILLIAN GONÇALVES ${ }^{1}$
}

\section{RESUMEN}

En el marco de las profundas transformaciones espaciales en la ciudad de Río de Janeiro, dada la realización de megaeventos, ocurren los más diversos tipos de violación de derechos. El derecho a la vivienda, violado a través de desplazamientos forzados y arbitrarios, se convirtió en el eje central de movimientos sociales que reivindican la ciudad. Este artículo toma em consideración determinadas luchas por el derecho a la ciudad, la vivienda digna y en contra de políticas urbanas clasistas y racistas. Además, se presentan formas de organización y lucha contra prácticas violadoras de los derechos humanos, y se analizan y evidencian las estratégias desarrolladas por el Estado aliado al capital para desarticular los movimientos de resistencia.

Palabras Clave: Rio de Janeiro, Megaeventos, desplazamientos, Favela, resistencia.

\footnotetext{
${ }^{1}$ Integrantes del Grupo de Investigación: Programa de Educação Tutorial (PET) de la Universidade Federal Fluminense (Brasil). R. Miguel de Frias, 9 - Icaraí, Niterói - RJ, 24220-900, Brasil. Correos electrónicos: andrealmeidaabreu@gmail.com, sreis.beatriz@gmail.com, michelvioleiro@gmail.com, renataseade@hotmail.com, thiagodamas@id.uff.br, willian-goncalves@hotmail.com.
} 
TO FIGHT, RESIST! VIOLATIONS TO THE RIGHT OF HOUSING AND POPULAR RESISTANCE IN THE SLUMS OF RIO DE JANEIRO IN TIMES OF MEGAEVENTS

\section{ABSTRACT}

Within the intense spatial transformations taking place in the city of Rio de Janeiro due to mega events, can be found the most diverse types of rights violations. The right to housing violated by forced and arbitrary removals became a central theme for social movements that claim the right to the city. Thus, the article analyzes some struggles for the right to the city, to decent housing and against classist and racist urban policies. In addition, here are forms of organization and struggle against practices of human rights violations. This article also intends to analyze and highlight the strategies developed by the state in addition to capital to dismantle the resistance movements.

Keywords: Rio de Janeiro, mega-events, displacements, Favela, resistance.

\section{LUTAR, RESISTIR! VIOLAÇÕES DO DIREITO À MORADIA E RESISTÊNCIA POPULAR NAS FAVELAS DO RIO DE JANEIRO EM TEMPOS DE MEGAEVENTOS \\ RESUMO}

No seio das intensas transformações espaciais que tem ocorrido na cidade do Rio de Janeiro, devido à conjuntura dos megaeventos, figuram os mais diversos tipos de violação de direitos. O direito à moradia, violado através de remoções forçadas e arbitrárias se tornou tema central dos movimentos sociais que reivindicam a cidade. Assim, o artigo contextualiza certas lutas pelo direito à cidade, à moradia digna e contra políticas urbanas classistas e racistas. Além disso, apresentamos aqui formas de organização e luta contra as práticas violadoras dos direitos humanos, além de analisar e evidenciar as estratégias desenvolvidas pelo Estado aliado ao capital para desarticular os movimentos de resistência.

Palavras chaves: Rio de Janeiro; Megaeventos; Remoção; Direitos Humanos; Favela; Resistência. 


\section{Introdução}

A coexistência de sujeitos sociais com diferentes lógicas econômicas e modos de vida faz do espaço um campo de confrontação de forças, dando-lhe uma dimensão essencialmente política. Dessa maneira, o espaço é objeto de intensos conflitos e alvo de ações carregadas de intencionalidade. $O$ ordenamento urbano consiste na face mais visível de tais intervenções materiais e simbólicas, que expressam a desigualdade das relações de poder na cidade. Atores hegemônicos como o Estado e setores empresariais impõem seus projetos ao conjunto da sociedade, encontrando às vezes resistências de populações organizadas através de movimentos sociais, associação de moradores ou ações coletivas. O que se assiste atualmente nas cidades brasileiras não constitui, em si, uma novidade, embora apresente novas facetas e um grau maior de complexidade no entrecruzamento dos atores sociais e na teia de relações envolvidas. Dessa forma, um primeiro passo consiste em tentar detectar as especificidades do processo de segregação decorrente da renovação urbana associada aos megaeventos contemporâneos, buscando situar rupturas e continuidades com relação a processos anteriores que caracterizam o urbanismo capitalista, atuantes não só no Brasil como nas mais diversas latitudes.

Da época dos barões de café à das construtoras de condomínios de luxo, o Estado tem atendido às preocupações empresariais das elites, em detrimento dos serviços sociais básicos para a população de baixa renda. Tais serviços não apresentam importância em si para o Estado, que só recebem investimento quando podem potencializar um projeto, atribuindo eficácia ao modelo econômico adotado. (Vainer, Maricato \& Arantes, 2000; Faulhaber \& Azevedo, 2015). O ordenamento territorial urbano é, portanto, fruto e semente do modo de produção capitalista, que traz consigo uma racionalidade funcional da cidade enxergando-a como mercadoria. Está engendrado na administração pública um alinhamento jurídico, político e ideológico alicerçado a um modelo de gestão e ocupação da cidade que condiciona a reprodução do capital financeiro a nível global, intensificando a fragmentação e segregação do espaço (Rolnik, 2014). 
Dentre as diversas transformações no espaço urbano do Rio de Janeiro, nos debruçamos sobre algumas obras recentes que vêm sendo executadas na Zona Oeste da cidade. Tal recorte espacial corresponde a um esforço para se compreender as mudanças da área onde está localizada a favela Vila União de Curicica, na qual realizamos uma pesquisa militante focada no papel das resistências sociais frente aos projetos que violam os direitos humanos.

No intuito de estreitar relações entre o ambiente acadêmico e as lutas populares, sob a crença na potencialidade de uma geografia capaz de associar teoria e prática política, consideramos imprescindível afirmar a não neutralidade deste trabalho, visto que se trata do resultado de um processo militante de pesquisa. Entende-se por "pesquisa militante", a produção de conhecimento comprometido com a transformação social, visando não só combater a invisibilização recorrente dos sujeitos subalternizados na Academia enquanto protagonistas de lutas sociais, mas também fazer do conhecimento científico um instrumento potencializador das lutas políticas. Dessa forma, nos reconhecemos enquanto pesquisadores militantes visto que essa pesquisa tem por objetivo não só documentar e analisar o processo de resistência da Comunidade Vila União de Curicica, mas também fortalecer a sua luta. É através da participação dos pesquisadores em reuniões semanais, manifestações, audiências públicas e outros ambientes de mobilização, que afirmamos nossa posição enquanto parceiros nessa resistência. A comunidade em questão é alvo do projeto de construção de um corredor de ônibus expresso que liga Recreio a Deodoro;denominado Transolímpica, esse projeto será melhor problematizado no final desse artigo.

Violações do direito à moradia são constantes nas cidades que foram sede dos megaeventos, que desde os anos 1980 se caracterizam por fortes processos de transformação urbana. No mundo, África do Sul, China e Índia, assim como o Brasil, foram e são palco para as remoções, para abrir lugar aos equipamentos esportivos, vias, aeroportos e obras de infraestrutura em geral. 
O projeto de construção das grandes vias para as Olimpíadas (Transoeste, Transcarioca, Transolímpica) é peça estratégica do desenvolvimento neoliberal no Rio de Janeiro ao articular a predominância do transporte rodoviário à valorização imobiliária. Não por acaso, novas grandes vias estão sendo construídas na Zona Oeste do Rio de Janeiro, escolhida estrategicamente para sediar grande parte dos eventos dos Jogos Olímpicos 2016, o que abriu pretexto para colocar em prática diversos projetos do setor imobiliário.

O papel do Estado, ao contrário do que propõem os teóricos do neoliberalismo, não é mínimo, sendo este um agente central para viabilizar as transformações urbanas, adaptando a cidade aos interesses dos grandes investidores. Nesse processo é fundamental a criação de um discurso de aceitação social das transformações decorrentes, supostamente oferecendo um "bem maior" à cidade e seus habitantes, discurso esse amplamente veiculado pela mídia. Assim, toda crítica que fere este modelo de urbanização é vista como contrário aos interesses gerais da cidade.

Os Jogos Olímpicos 2016 são vistos com bons olhos pelos agentes hegemônicos que organizam o megaevento, pois são uma boa oportunidade de vender o modelo de desenvolvimento urbano que proporciona uma acumulação ainda maior por parte das empresas. Dessa forma, as remoções forçadas em áreas de interesse servem para viabilizar esses investimentos. São uma "fronteira econômica" para onde se expandem os empreendimentos impulsionados pelas imobiliárias, construtoras e incorporadoras. Há, no entanto, o problema de vender a imagem de uma "Barra Olímpica" numa área rodeada de favelas, paisagem indesejada no cenário idealizado para os Jogos. A acumulação capitalista, para estes produtores do espaço, só é possível através da espoliação da população pobre local, entendida por estes como um obstáculo a seus projetos (Harvey, 2003). O fato é que o panorama atual do Rio de Janeiro apresenta transformações que sem dúvida trazem um modelo de desenvolvimento à custa da expulsão de populações mais pobres dessas regiões, seja através da elevação do custo de 
vida (a chamada remoção branca) ou através da força bruta do Estado, removendo de forma compulsória parcelas dessa população (Harvey, 2003).

No entanto, em contraposição ao modelo de cidade-empresa, surgem e se fortalecem movimentos e ações coletivas que lutam pelo direito à cidade. Tais formas de organização social que questionam projetos urbanos dessa natureza lutam por direito à voz e participação na produção e organização da cidade. Isto evidencia um conflito de interesses entre os que veem o espaço apenas como uma via para o lucro e os que veem no espaço a reprodução de seu cotidiano e um possível caminho para garantir seus direitos.

\section{A cidade Olímpica: Reordenamento Territorial na Zona Oeste do Rio de Janeiro}

Na medida em que novos objetos geográficos são criados a partir de um conjunto de ações, viabilizam-se práticas sociais de produção do espaço. A cidade nos traz em sua paisagem uma acumulação de diferentes tempos históricos e técnicas especialmente municiadas para suprir demandas da organização social de cada período (Santos,1991). Assim, a cidade se expande externa e internamente, levando ao avanço da fronteira urbana. No caso do Rio de Janeiro, esse avanço atinge o que hoje é conhecido como Zona Oeste da cidade, que em meados do século XX apresentou grande crescimento de sua malha urbana. Antes desse período, a região se destacava por sua produção agrícola e de pescado que abastecia as áreas centrais da cidade.

Identificamos na Zona Oeste um vasto conjunto territorial inserido na metrópole. Ela corresponde a cerca de $60 \%$ da área do município e abriga mais de 2 milhões de habitantes, abrangendo bairros populosos como Campo Grande, Jacarepaguá, Barra da Tijuca, Sepetiba, Santa Cruz, entre outros. O processo de ocupação da região acontece de forma bem heterogênea, variando desde compra e venda de loteamentos, usucapião e empreendimentos imobiliários. Dentro desse recorte regional, daremos enfoque à Área de Planejamento 4 (AP4) delimitada pela Prefeitura do Rio de Janeiro. Essa área se estende também a outros 
municípios, que fogem ao nosso eixo de interesse. Concentraremos nossa atenção, portanto, no conjunto Barra da Tijuca-Jacarepaguá-Curicica.

Figura 1. Áreas de Planejamento e Regiões Administrativas do Rio de Janeiro

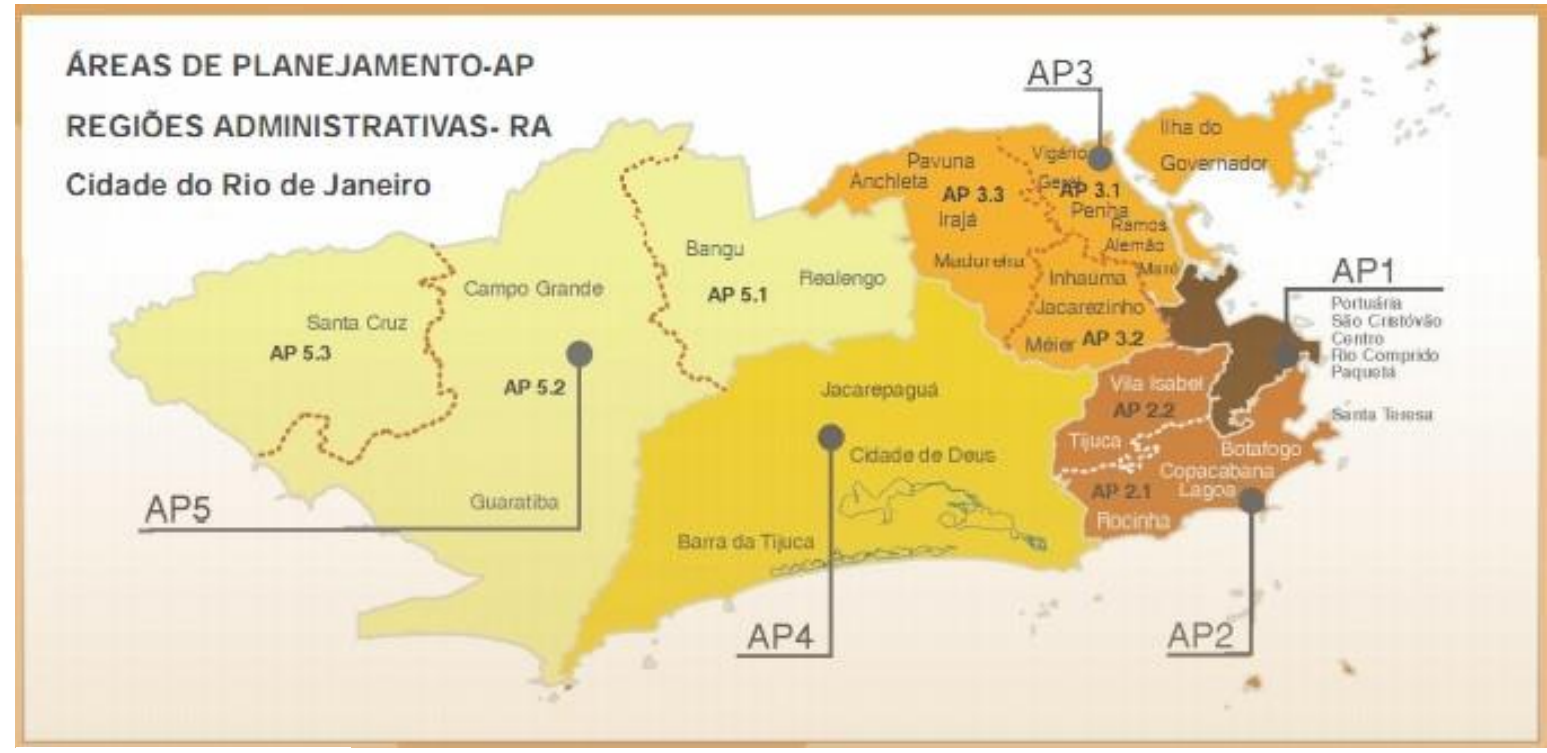

Fonte: Rio On Watch

O crescimento urbano da Barra da Tijuca apresenta características particulares, levando em consideração a evolução verificada em outras áreas da cidade. O regime militar brasileiro, instalado após o golpe de 1964, intensificou o processo de concentração de renda e desenvolveu uma política habitacional questionável em diversos aspectos. No Rio de Janeiro, o governo criou um órgão destinado a remover favelas das áreas mais nobres da cidade, denominado Coordenação de Habitação de Interesse Social da Área Metropolitana (CHISAM). Com isso, a Zona Sul ratifica sua posição de reduto das elites, contando com casas luxuosas e morros livres de ocupações populares que resistiam no local. Grande parte da população favelada foi removida. Algumas pessoas foram deslocadas para conjuntos habitacionais distantes de onde trabalhavam e haviam organizado suas vidas, tais como a Vila Kenedy (às margens da Avenida Brasil, no bairro periférico de Bangu), enquanto outras ficaram completamente marginalizados do direito à moradia. 
Associado ao aumento da concentração de renda e à necessidade de expansão dos investimentos, ocorreu um intenso processo de especulação imobiliária, expandindo a zona rica da cidade para São Conrado e Barra da Tijuca. Mais uma vez, o papel do Estado foi o de prover a infra-estrutura necessária para o mercado imobiliário, deixando de lado o investimento em outras áreas da cidade que, muitas vezes, se encontravam ainda carentes de serviços básicos.

Data do fim da década de 60 a construção da primeira etapa da Auto-Estrada Lagoa-Barra, um investimento caríssimo que inclui a perfuração de vários túneis e a construção de um trecho em pistas superpostas encravadas na rocha. (...) é através dessas novas vias que o núcleo metropolitano se expande. (...) o Estado em associação com o capital privado - já vem investindo grandes somas na sua [Barra da Tijuca] "preparação" (abertura de estradas e ruas, pavimentação, iluminação pública, instalação de infraestrutura, etc.), em detrimento de investimentos mais urgentes e mais necessários que poderiam ser realizados nas zonas suburbanas da cidade ou na periferia metropolitana. (Abreu, 1987, p.145)

$\mathrm{Na}$ Barra da Tijuca a ocupação passa a acontecer sob a égide de uma nova tendência do capital: a transformação da propriedade, e com isso do direito de produzir cidade, em ativo financeiro. Esta tendência gera uma novidade também no âmbito da gestão urbano, através da divisão da cidade em Áreas de Planejamento (APs). A lógica das APs divide o Rio em eixos de valorização que, por sua vez, guiam os investimentos do planejamento urbano.

É importante lembrar que existem áreas da cidade que não operam exatamente segundo a lógica do capital. Ocupações e títulos de propriedade adquiridos através de usucapião eram práticas comuns na realidade da cidade. As favelas são um exemplo disso: os acordos envolvendo aluguel e propriedade se davam muitas vezes de forma independente do mercado formal, com valores alheios à especulação e contratos apalavrados. (Abreu, 2011) (Abreu, 2014); (Silva, 2003); (Souza \& Silva, 2002). Com a volatilização do capital, através do rentismo e da financeirização da economia, dificultam-se essas formas de troca local. As relações informais da economia perdem muita força, pois se veem pressionadas pela valorização da região, que atrai atividades ligadas ao mercado formal. Com as APs, o solo urbano é fragmentado em fatias e vendido no mercado 
para setores empresariais, que não levam em conta essas relações informais, e tendem a especular na área até que haja um maior fluxo de investimentos em sua direção.

Podemos dizer, então, que o Estado dá o primeiro passo ao criar condições para a valorização de uma área, o que atrai o interesse do capital especulativo e garante o desenvolvimento do capital produtivo. A este papel impulsionador do Estado chamaremos aqui de marco zero. No caso do Rio de Janeiro, a Prefeitura compartilha o planejamento da cidade com o capital privado, através das Parcerias Público-Privadas (PPP) que atuam em obras de saneamento, infraestrutura e áreas de lazer, valorizando economicamente a região. Em teoria, parecem medidas com interesse social, mas o resultado é bastante contraditório: essas obras, que deveriam atender os interesses da sociedade civil, são na verdade responsáveis pelas remoções, compulsórias ou não, dos moradores nas áreas afetadas. É notório que a intenção das obras de infraestrutura é abrir espaço para novos investimentos que, por sua vez, concretizam na cidade apenas os interesses dos grupos investidores, articulados em nível global numa complexa teia que une setores do capital financeiro, industrial e imobiliário. O resultado desta aliança, conforme Pinto (2014), é a mercantilização sem precedentes do solo urbano; surgem condomínios corporativos, residenciais de luxo e escritórios sedes de multinacionais, construções que favorecem os interesses do mercado especulativo em detrimento do interesse social.

A reprodução do capital financeiro - através da produção de edifícios de escritórios voltados à realização dos setores modernos da nova economia que se instala na metrópole - se realiza através das novas articulações entre os capitais individuais e privados, setores diferenciados sob o comando do Estado. Através dos fundos imobiliários e do mercado financeiro forma-se uma nova articulação entre os setores industrial e imobiliário, posto que não se trata da construção dos edifícios para sua venda. $\mathrm{Na}$ realidade esse capital industrial/financeiro vai produzir os edifícios corporativos direcionados ao novo setor da economia, num momento em que as transformações do processo produtivo, diante das novas condições de competitividade do mercado, tornam impossível a imobilização do capital na compra do imóvel, o que oneraria os custos de produção. Portanto, para continuar se reproduzindo o faz através da compra da terra urbana (que é o que vai se constituir no eixo empresarial e comercial) onde vamos encontrar as sedes das empresas. Portanto, o capital acumulado no processo industrial vai ser 
aplicado na produção de imóveis, mas com características precisas: a construção de edifícios inteligentes voltados para o setor de aluguel, em função das novas atividades econômicas. Do ponto de vista do solo urbano o processo atual exige a superação de sua condição de fixidez. (Pinto, 2014, p. 5)

Transformar o Rio em Cidade Olímpica implica em ativar o chamado marco zero, ou seja, as Olimpíadas funcionam como uma espécie de "gatilho" para o Estado assumir o papel que lhe compete nesse processo. No caso do Rio de Janeiro, as PPPs determinam áreas de interesse para a iniciativa privada, fazendo dela uma aliada do Estado no planejamento de obras de infraestrutura - como os corredores Bus Rapid Transit, popularizados através da sigla BRT - que, por sua vez, beneficiam os projetos do mercado imobiliário e especulativo. Dessa forma, o que se vê é a remoção compulsória como forma de abrir espaço para uma fronteira de acumulação que deseja especular o espaço urbano e, para isso, demanda o desalojamento da população pobre das áreas de interesse do capital.

Com base no acompanhamento do processo de remoção, fica evidente que é de praxe a implementação dos projetos de maneira autoritária, sendo os canais de participação meramente formais, quando não irrisórios. Dessa maneira, sua aprovação não leva em consideração a população residente e seu modo de vida, não estabelecendo com ela nenhum diálogo e, em muitos casos, nem mesmo ocorre uma consulta prévia, conforme será explicitado mais a diante. Para discutir impactos dessa natureza na cidade, destacaremos dois projetos recentes na AP4, no eixo Barra da Tijuca-Taquara-Curicica: o projeto Barra Olímpica e os modais rodoviários BRT.

\subsection{O projeto Barra Olímpica e o avanço da fronteira Imobiliária na AP4}

A Zona Oeste, principalmente a Área de Planejamento 4, está no bojo das transformações urbanas já mencionadas neste trabalho, e não é por acaso. Considerando que o Centro da Cidade, Zona Sul e boa parte da Barra da Tijuca já apresentam uma urbanização bem consolidada, a tendência é que a malha urbana siga sendo ampliada e mercantilizada, dentro da lógica financeira, para áreas de ocupação mais esparsa. Isto facilita não só as construções propriamente ditas, 
mas também os mecanismos de remoção de ocupações pré-existentes para a construção em larga escala de condomínios residenciais e prédios de escritórios comerciais. Ao tratar do boom imobiliário na Barra da Tijuca e Baixada de Jacarepaguá, Pinto (s/d) nos ajuda a compreender os níveis de crescimento de outros bairros da AP4 na atualidade:

(...) essa lógica só se reproduz em espaços com grandes áreas ainda disponíveis. No caso da cidade do Rio de Janeiro, no atual momento, espaços que respondem às demandas da lógica financeira, se localizam em grande parte na zona oeste da cidade. (...) assim, os espaços livres disponíveis, além de servirem para a efetivação da expansão da malha urbana da cidade, promoviam a reprodução do capital no espaço urbano carioca. (...) O fomento ao setor imobiliário ocorrido principalmente na década de 1970 na Barra da Tijuca e na Baixada de Jacarepaguá, fundou os pilares da construção massiva de edifícios residenciais nas décadas de 1980 e 1990.

Nos moldes desse crescimento, podemos notar a expansão do mercado imobiliário no sentido Sul-Norte, se expandindo da Barra da Tijuca à Jacarepaguá chegando em Curicica. Na saída da serra Grajaú-Jacarepaguá é bastante marcado na paisagem o avanço do capital imobiliário. Diversos apartamentos em condomínios fechados, aluguel de escritórios ou mesmo placas de edificações ainda não construídas compõem o cenário desse bairro da Zona Oeste.

Em meio a essa conjuntura, é apresentado à Câmara dos Vereadores do Rio de Janeiro um projeto de lei n 807/2010 de autoria do Vereador Carlo Caiado (DEM). O projeto tem como objetivo a criação de um novo bairro na interseção dos bairros da Barra da Tijuca, Camorim e Jacarepaguá. A justificativa apresentada no projeto diz respeito à recepção dos Jogos Olímpicos de 2016, como se a cidade precisasse marcar no seu espaço-tempo a recepção do evento. Carlo Caiado assim justifica seu projeto:

A realização na Cidade do Rio de Janeiro de um evento da magnitude dos Jogos Olímpicos, em 2016, representará, não temos dúvida, um marco para toda a Cidade e nosso povo. Afinal, como se costuma dizer, os olhos do mundo estarão voltados para nossa terra, pois serão mostradas, a par dos eventos esportivos propriamente ditos, as incomparáveis belezas da Cidade. Esta, portanto, é uma oportunidade ímpar, que merece, e precisará, ser lembrada para sempre, de todas as maneiras possíveis. Daí a motivação para a presente iniciativa, que pretende registrar indelevelmente os Jogos Olímpicos da Cidade do Rio de Janeiro, que certamente se constituirão em um dos mais memoráveis Jogos Olímpicos de toda 
a história desse grandioso evento mundial. (Câmara Municipal do Rio de Janeiro, 2014)

Antes de se tornar Vereador, o parlamentar atuou na subprefeitura da Barra da Tiuca e Jacarepaguá e foi também administrador regional do Recreio dos Bandeirantes. Não seria exagero considerar que a criação deste novo bairro indica o alinhamento político do Legislativo com os interesses da especulação imobiliária e das empreiteiras, conforme demonstrado por Faulhaber (ver figura 2 em seguida) e, de certa forma, comprovado pelo movimento do mercado imobiliário em direção à área.

A região correspondente ao novo bairro conta com uma rica história de resistência de remanescentes quilombolas, pescadores e agricultores familiares que terão seus direitos feridos e, muito provavelmente, serão expulsas de seus locais de origem. O projeto de Lei foi parcialmente vetado na câmara, mas segue em tramitação.

\section{Figura 2 - Lotes Desapropriados que coincidem com Lançamentos Imobiliários}

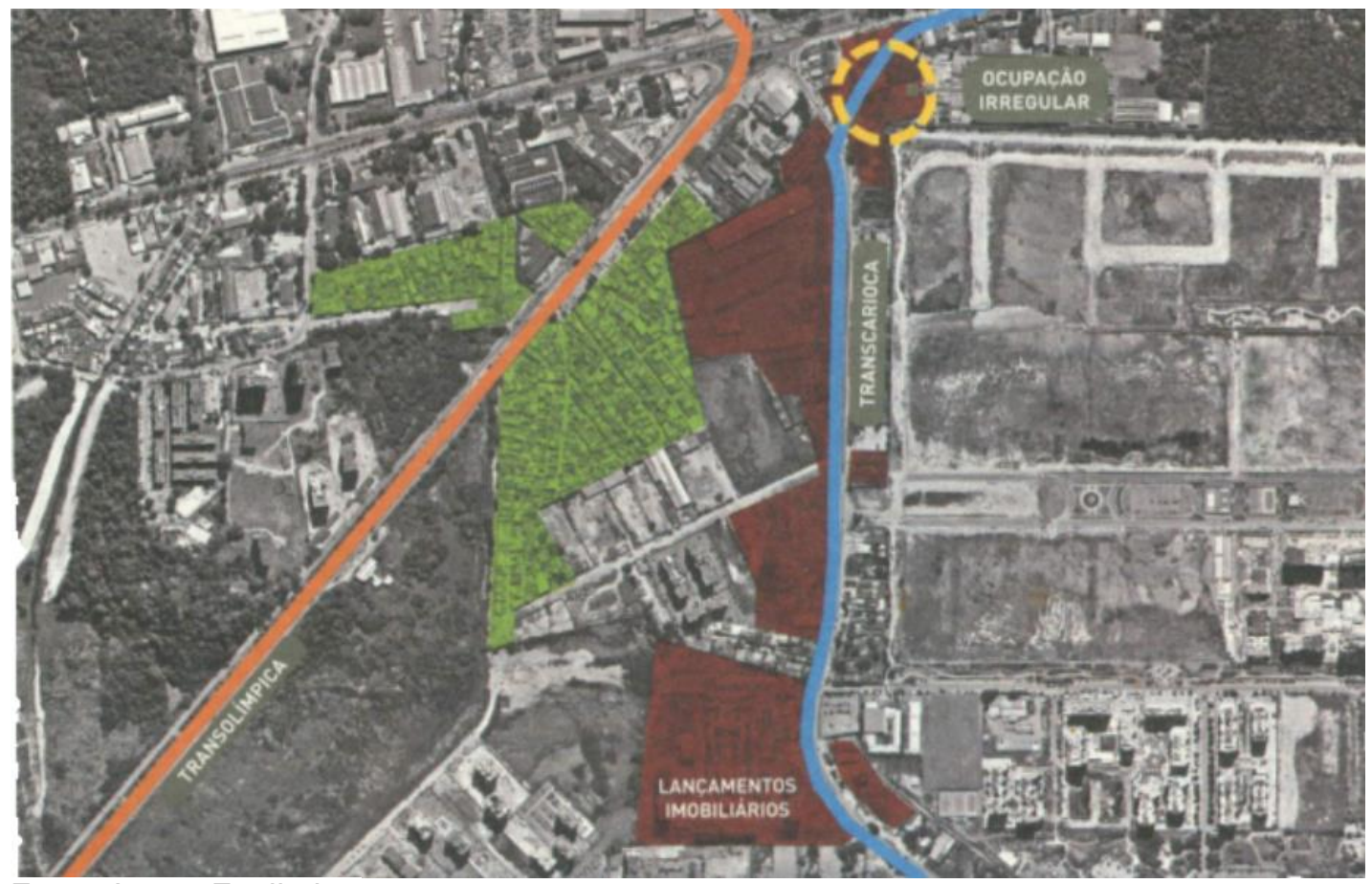

Fonte: Lucas Faulhaber 
Como se nota, o mapa (figura 2) apresenta áreas desapropriadas (em vermelho) durante a construção da Transcarioca onde posteriormente foram lançados empreendimentos imobiliários. É possível perceber claramente no trecho circulado em amarelo, que se optou por projetar a via em cima de uma ocupação já consolidada, quando seria possível definir um trajeto alternativo (Faulhaber, 2015). Em verde, se observam as áreas favelizadas ameaçadas de remoção, logo ao lado da área de interesse do mercado imobiliário, o que demonstra a indissociabilidade entre a remoção das moradias de população pobre e a valorização imobiliária da área.

O mercado imobiliário, cuja especulação está diretamente ligada ao processo de remoção de favelas do Rio, vê com bons olhos a criação de um novo bairro nesta área sob o nome de Barra Olímpica. A população, no entanto, não clama pela criação de um bairro novo como legado olímpico embora um vereador, enquanto representante do povo, traduza nessa narrativa o modus operandi do mercado ao procurar eternizar o megaevento na cidade dessa forma. Cabe lembrar que a Zona Oeste da cidade é hoje uma fronteira de expansão imobiliária, fazendo com que a situação apresentada se traduza, para nós, como um claro exemplo do alinhamento entre interesses políticos e de mercado.

\subsection{BRT: os megaprojetos viários da 'Cidade Olímpica'}

Com intuito de dinamizar o transporte de pessoas pela cidade, principalmente no período dos jogos olímpicos, três megaprojetos rodoviários estão em execução no Rio de Janeiro. São os chamados Transcarioca, Transolímpica e Transoeste. Trata-se de grandes corredores viários de sistema BRT (Bus Rapid Transit) que conta com ônibus articulados que comportam maior quantidade de passageiros que ônibus comuns. Boa parte dessas obras é financiada pelo Governo Federal e realizada sob a responsabilidade da Prefeitura Municipal do Rio de Janeiro, contando também com a participação da iniciativa privada. Os eixos viários são implantados ora em vias já existentes (reformadas 
e/ou ampliadas), ora em novas vias, envolvendo também a construção de túneis, pontes, viadutos e mergulhões.

A Transoeste foi a primeira via inaugurada. O corredor BRT liga a Barra da Tijuca e Recreio dos Bandeirantes até Santa Cruz e Campo Grande. A Transcarioca passa por 27 bairros desde a Barra da Tijuca até a llha do Governador (Aeroporto Internacional Tom Jobim). São as seguintes: Barra, Jacarepaguá, Curicica, Cidade de Deus, Taquara, Tanque, Praça Seca, Campinho, Madureira, Cascadura, Engenheiro Leal, Turiaçu, Vaz Lobo, Vicente de Carvalho, Irajá, Vila da Penha, Vila Kosmos, Brás de Pina, Penha Circular, Penha, Olaria, Ramos, Bonsucesso, Complexo do Alemão, Maré, Fundão e Galeão. Por fim, a Transolímpica vai cortar os bairros Magalhães Bastos, Curicica e Sulacap, fazendo ligação com a Transcarioca, em Curicica, e com a Transoeste, no Recreio dos Bandeirantes. Além disso, irá se interligar a outros modais como os trens da Supervia, no bairro de Deodoro. A construção dessa infraestrutura não foge ao padrão descrito anteriormente de como o poder público conduz seus projetos.

\section{Figura 3 - BRTs planejados para o Rio} de Janeiro

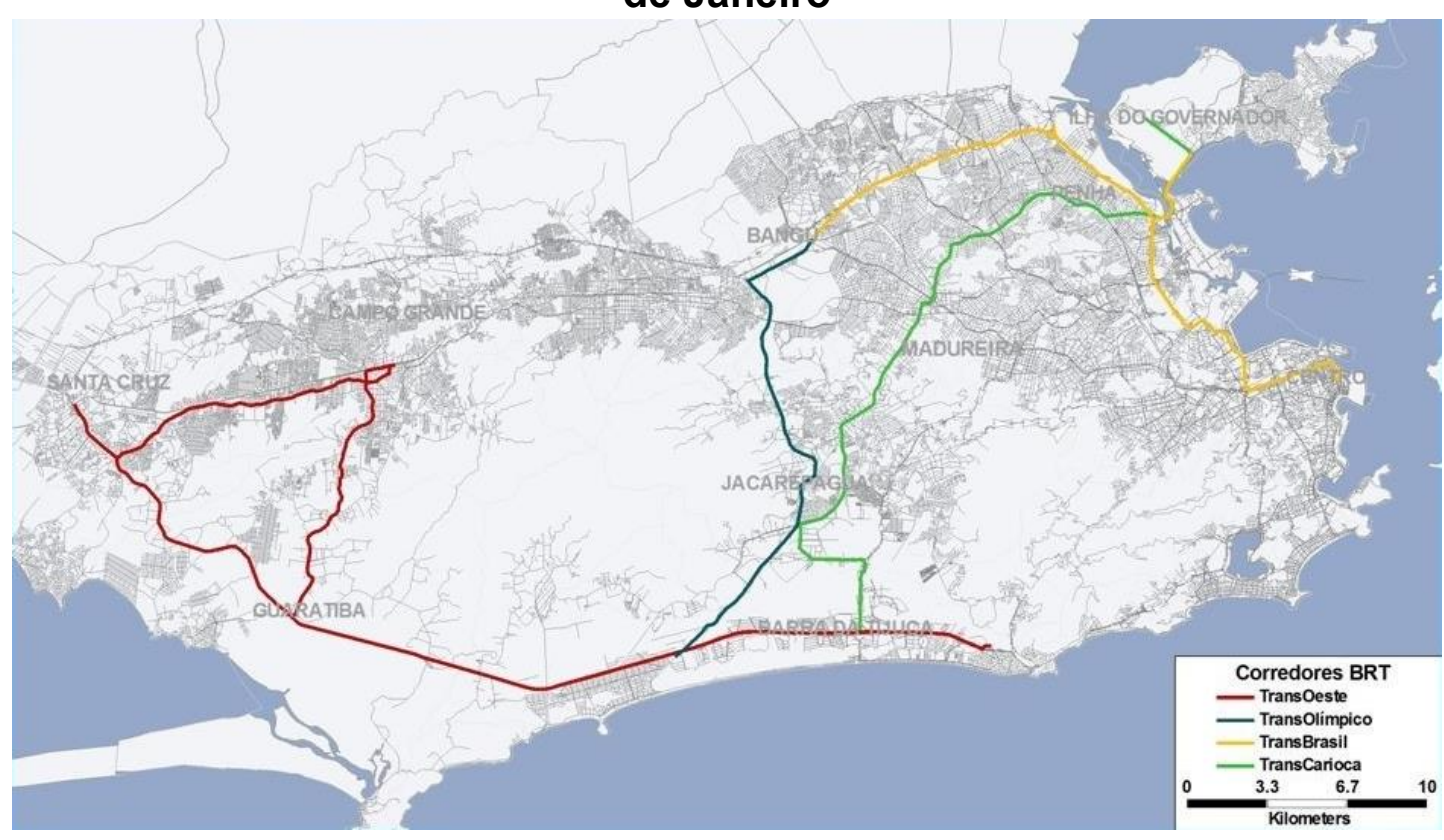

Fonte: Prefeitura do Rio de Janeiro 
Segundo o Dossiê do Comitê Popular da Copa e Olimpíadas Rio de Janeiro (2013), as obras do Projeto Transcarioca já removeram no mínimo 532 famílias em diversos lugares, tais como Vila das Torres, Arroio Pavuna, Largo do Tanque, Rua Quáxima e Comunidade do Campinho. Fontes desse dossiê mostram que as obras do Projeto Transoeste já removeram no mínimo 537 famílias em localidades como a Comunidade Restinga, Vila Harmonia, Comunidade Vila Recreio II, Notredame e Vila Amoedo. A Prefeitura ainda prevê uma série de remoções para as obras tanto da Transcarioca como da Transoeste. O Dossiê de 2013 não atualizou as remoções ocorridas na Transolímpica, mas ressalta as diversas desapropriações previstas para as obras da via.

Vale salientar a insistência da Prefeitura em investir no transporte rodoviário. Embora afirme que o sistema BRT é um transporte de massas, é duvidoso que sua capacidade de transporte seja a mesma de trens e metrôs, considerando que o metrô, por exemplo, transporta aproximadamente $700 \mathrm{mil}$ pessoas por dia, enquanto o BRT no ano em que realizamos nossa pesquisa militante transportava cerca de 300 mil pessoas diariamente. Não consta que se tenha cogitado a construção de uma via subsuperfície, o que evitaria remoções de população. O que está em jogo, certamente, são interesses econômicos de determinados setores. Em nível local, temos os empresários de ônibus, com forte presença política em âmbito municipal. Numa escala mais ampla, que pode inclusive transcender o âmbito nacional, temos os atores sociais que apostam suas fichas na transformação do espaço geográfico da área através de um conjunto de investimentos, promovendo a valorização do solo urbano e consequentemente a remoção de pessoas menos abastadas. $O$ encadeamento de fatores em favor da via de superfície, portanto,encontra sua explicação.

Como se não bastassem essas questões com forte significado social, existem denúncias de irregularidades e superfaturamento das obras. A título de exemplo, vejamos alguns dados referentes à Transcarioca. Incluída no Programa de Aceleração do Crescimento (PAC) da Mobilidade Urbana, a via foi orçada inicialmente em $\mathrm{R} \$ 790$ milhões; no entanto, segundo o Tribunal de Contas da 
União, seu custo mais que dobrou, alcançando a cifra de $\mathrm{R} \$ 1,8$ bilhão (COMITÊ POPULAR COPA RIO E OLIMPÍADAS, 2013).

Como em todas as experiências de implantação de corredores viários em áreas periféricas, tal como analisado por Faulhaber (2015), a ausência de discussão com as populações atingidas diretamente é a tônica. O projeto é autoritário, não havendo nenhum tipo de consulta popular em sua elaboração. Com isso, inúmeras pessoas são penalizadas, ficando sujeitas a remoções compulsórias, indenizações nem sempre satisfatórias ou projetos de habitação populares extremamente precários. Acima de tudo, têm seus direitos feridos pelo autoritarismo e desrespeito com que o poder público conduz o processo. É exatamente isso que acontece com os moradores da comunidade Vila União, no bairro de Curicica, onde cerca de 900 famílias foram notificadas de forma inesperada que seriam atingidas pelo traçado da Transolímpica. Trataremos deste caso a seguir.

\section{Vila União Curicica}

A comunidade Vila União de Curicica, localizada na Zona Oeste da cidade, sofre ameaças de remoção. Devido à sua proximidade com o Parque Olímpico e por ser uma área de interesse da especulação imobiliária, a comunidade poderá ser extinta, dando lugar à grande via denominada Transolímpica, destinada a ligar os bairros da Barra da Tijuca e Deodoro.

Com quase 30 anos de existência e abarcando aproximadamente mil famílias, a Vila União já foi objeto de outros projetos de políticas públicas. Até recentemente, a localidade seria contemplada com obras do programa "Morar Carioca", que visava à urbanização da área. Tal projeto foi recebido com grande entusiasmo pelos moradores, pois previa investimentos em infra-estrutura com enfoque na inclusão urbana e social. Vale destacar que o projeto pretendia ainda regularizar urbanisticamente as comunidades. Atualmente, porém, a Vila União de Curicica foi retirada do programa "Morar Carioca"e os moradores ameaçados de remoção poderão ser reassentados em apartamentos localizados em um bairro vizinho. 


\subsection{Estratégias do poder público}

Em nome dos megaeventos e em alinhamento com os interesses de grandes empresas dos ramos imobiliário, transportes e construção civil, o poder público utiliza as remoções de comunidades como artifício recorrente para viabilizar projetos urbanísticos na cidade. Foram mais de 700 casos de remoção para a construção dos BRTs Transoeste e Transcarioca e agora, para a construção do BRT Transolímpica se prevê a remoção de cerca de 900 famílias na Vila União Curicica.

É de conhecimento público que, após a Declaração Universal dos Direitos Humanos, aprovada em 1948 na ONU, diversos tratados internacionais determinaram como responsabilidade dos Estados a promoção e proteção do direito à moradia. Dessa forma, existem hoje normas internacionais que se opõem a remoções involuntárias decorrentes de projetos públicos e privados de infraestrutura e urbanização. Porém, no caso do Rio de Janeiro, são identificadas constantes violações aos direitos das comunidades ameaçadas de remoção por parte da Prefeitura, como forma de agilizar e baratear o processo de saída das famílias.

São muitas as estratégias utilizadas pelo governo para viabilizar as remoções e, seguindo o fluxo contrário dos acordos assinados junto à ONU, muitas delas revelam o caráter antidemocrático das decisões que envolvem as reformas urbanísticas da cidade. Isto é, desde a elaboração do traçado até a demolição das casas, ações e decisões vem sendo tomadas de forma autoritária, sem a devida consulta popular, restando à comunidade apenas a opção de se adequar à situação, aceitando o que for oferecido pela Prefeitura, com pouca abertura para diálogo e negociação.

Em Curicica ocorrem inúmeras ações que contradizem o direito à moradia. Entre as principais estratégias utilizadas pela Prefeitura está a falta de informações: não houve acesso ao projeto da BRT Transolímpica por parte dos moradores, que tampouco foram informados sobre a data das demolições, agravando a sensação de pânico, insegurança e impotência dos atingidos. No 
posto de informações colocado na comunidade é prestado apenas o serviço de cadastramento dos moradores, facilitando o controle da prefeitura.

A demolição progressiva das residências também figura entre as ações do poder público que contradizem o direito à moradia, fazendo com que os habitantes da localidade vivam constantemente sob pressão, e em contato com os escombros. Foi observada, também, a estratégia de aparelhamento da Associação de Moradores da comunidade, que passou a defender pontos de vista próximos ao projeto apresentado pela Prefeitura, gerando descontentamento por parte dos moradores. Verificou-se que a parcela dos moradores interessados em resistir ao processo de remoção passou a não se sentir representada pela Associação, perdendo assim uma importante ferramenta de articulação de luta coletiva.Em nome da prefeitura foram apresentadas três opções aos moradores: Indenização, Aluguel Social ou Apartamentos no Programa Minha Casa Minha Vida (MCMV). Um dos maiores motivos de revolta entre os atingidos diz respeito às negociações frente a estas opções, devido os seguintes fatores: ofertas de indenização extremamente abaixo do valor de mercado; negociações individuais de indenização, com ofertas em diferentes valores; proposta de aluguel social por três meses no valor de quatrocentos reais ( $R \$ 400,00)$ - valor muito abaixo do mercado, levando em consideração que o Rio de Janeiro figura entre as cidades mais caras do mundo -; apartamentos significativamente menores do que as casas dos moradores na comunidade, oferecidos através do MCMV; falta de informações acerca da disponibilidade de apartamentos para todos, além da incerteza em relação ao tempo que os apartamentos levariam para ficarem prontos.

Entre casas marcadas com as iniciais da Secretaria Municipal de Habitação $(\mathrm{SMH})$ e relatos de tentativas de intimidação por parte do poder público, uma das práticas mais chocantes exercidas é a desassistência no que diz respeito aos serviços públicos básicos, denunciada pelos moradores durante as reuniões do Movimento Independente Popular de Vila União. Como forma de desestimular a resistência dos atingidos, serviços como coleta de lixo, manutenção de postes de 
luz e limpeza do valão estão sendo abandonados pela Prefeitura, numa clara tentativa de pressionar os moradores e "vencê-los pelo cansaço".

Dessa forma, é possível afirmar que, no contexto das remoções, o Estado tende - desde o início do processo - a se posicionar contra os interesses e necessidades da população, agravando o desespero das famílias através de estratégias autoritárias e coercitivas.

\subsection{Formas de Resistência}

Levando em consideração o cenário das recentes remoções no Rio de Janeiro, constantemente marcadas por estratégias desleais e arbitrárias da Prefeitura, resta aos moradores a incessante busca por formas de organização que possam fortalecê-los perante aos abusos do poder público. Neste sentido, a luta de resistência vai muito além da simples união dos moradores em prol de um objetivo comum; como em toda luta, é necessário identificar aliados, inimigos e estratégias. Em linhas gerais, os pontos fortes das ações resistência dos moradores da Vila União Curicica consistem na articulação com movimentos sociais e parlamentares cujas pautas já apresentavam experiências na área dos direitos humanos e/ou luta contra remoções, como a parceria com a Comissão de Direitos Humanos da Associação Brasileira de Imprensa (CDHABI). Essas articulações têm, entre outros objetivos, denunciar as ilegalidades e violações de direitos promovidas pelo Estado em Vila União.

Parte dessas formas de articulação são estabelecidas entre os próprios moradores, das quais podemos destacar: a ocorrência de encontros constantes em reuniões para repasse de informações; a divisão de tarefas entre os militantes gerando o empoderamento de todos dentro do movimento; documentação em vídeo das reuniões mais importantes; identificação e documentação das casas ameaçadas através de fotografias, além da presença e constante divulgação do movimento nas redes sociais.

Entre as possibilidades de articulação com a sociedade civil organizada, na busca por apoio e visibilidade, podemos citar: a união com outros movimentos de 
resistência à remoção como a Vila Autódromo e Vila Indiana, bem como o Comitê Popular da Copa e Olimpíadas; núcleos universitários de pesquisa e extensão; e grupos de mídia alternativa. Como Rio On Watch e a revista Vírus Planetário. Foram realizados atos públicos em Curicica com presença dos moradores em manifestações de rua, com o apoio de outros movimentos de resistência ligados aos megaeventos como o 'Ocupa Golfe' e o Comitê Popular da Copa e Olimpíadas do Rio de Janeiro.

O Comitê Popular da Copa e Olimpíadas é composto por diversas organizações, lideranças populares, movimentos sociais e pessoas atingidas pelas ações arbitrárias do Estado. Ele atua não só na elaboração de dossiês denunciando essas arbitrariedades, mas também organizando e dando suporte à diversas formas de mobilização, além de pressionar a prefeitura para estabelecer um processo mais democrático de discussão sobre qual deve ser o real legado dos Megaeventos. O movimento "Ocupa Golfe" é uma ocupação política que contesta a legalidade da construção de um campo de golfe no antigo Parque Natural Municipal de Marapendi na zona Oeste do Rio de Janeiro. Após os jogos Olímpicos, a prefeitura destinará essa área à iniciativa privada e o projeto prevê a construção de um condomínio de luxo no local. Dessa forma, o movimento questiona principalmente a falta de transparência nas contas da prefeitura em relação ao projeto e a legalidade da licença ambiental concedida para a construção do empreendimento, tendo em vista que se trata de uma área de proteção ambiental.

Vale destacar a extrema importância da articulação com o Comitê Popular da Copa e Olimpíadas, visto que se trata do segmento de um movimento nacional contra as violações de direitos humanos oriundos das políticas públicas relacionadas aos megaeventos. A aproximação entre o Comitê e o Movimento Independente Popular de Curicica - como passou a ser chamado - foi responsável por dar destaque à luta frente a tantos casos de remoções verificados na cidade. Tal articulação com um movimento desta dimensão ampliou a rede de 
contatos e aliados, além de impulsionar a velocidade das conquistas reais do movimento.

$\mathrm{Na}$ busca por representatividade junto ao poder público, destacamos a procura por parlamentares que possam representar o movimento dentro das Câmaras. Desta forma, foi estabelecido contato com diversos vereadores e deputados estaduais embora poucos tenham se comprometido com a causa, como os deputados estaduais Janira Rocha e Paulo Ramos (ambos do PSOL), que prestaram auxílio através de pronunciamentos na Câmara e assessoria com procedimentos padrões para solicitação de audiência pública. Outra frente de resistência neste contexto consiste na representação através da Defensoria Pública. Com isso, é possível perceber a importância da manutenção de uma rede diversificada de aliados na luta de resistência, sejam eles parlamentares, movimentos sociais ou membros da sociedade civil engajados na causa.

\subsection{Avanços da Resistência}

O processo de remoção que atinge a Vila União Curicica está longe de alcançar seu desfecho. Mesmo assim, é possível destacar situações promissoras resultantes da organização dos moradores. A partir da mobilização local os moradores tornaram públicas as violações dos direitos humanos e ganharam aliados em diversos setores anteriormente citados. Entre avanços e impasses, o Movimento Independente Popular de Vila União Curicica vem colhendo os frutos da luta organizada.

Entre os resultados mais importantes do processo de resistência, pode-se citar a apresentação de um novo trajeto para a TransOlímpica. Em dezembro de 2014 a Prefeitura apresentou formalmente à comunidade a ideia de alterar o traçado da via, diminuindo bastante o número de famílias por ela atingidas. Porém, como foi dito, a falta de informações claras é uma estratégia usada pela Prefeitura para desarticular a mobilização e, por isso, este novo trajeto apresentado foi recebido com cautela pelos moradores. 
Já em 2015, em contato com os moradores, representantes da Prefeitura frisaram que a alteração do traçado original se trata apenas de uma possibilidade reforçando a ideia de que esta promessa pode ser apenas mais um recurso estratégico do poder público. Ainda assim, a simples abertura de diálogo entre Prefeitura e moradores sobre o projeto já pode ser considerada uma vitória da pressão popular, que se organizou o suficiente para resistir e conquistar canais de diálogo, antes bastante precários. Vale ressaltar, porém, que os moradores de Vila União ainda não estão satisfeitos com o projeto apresentado formalmente em dezembro de 2014.

Em 2015, o Movimento Independente Popular de Vila União conseguiu, através de parlamentares que apoiavam sua causa, marcar duas audiências públicas para discutir com as autoridades e a imprensa possíveis soluções para o conflito. Ao mesmo tempo, denunciavam as diversas violações de direitos humanos provocadas pelo processo de remoção.

Na primeira audiência, realizada na Assembleia Legislativa do Estado do Rio de Janeiro, a Associação de Moradores de Vila União, munida pela subprefeitura da Barra da Tijuca, levou para o fórum um ônibus com moradores vestindo camisas e carregando faixas com frases em defesa das ações da Prefeitura. A estes moradores foram prometidas casas sem qualquer projeto além daquele previamente apresentado, que oferecia um conjunto de apartamentos de 37 metros quadrados no colonial Juliano Moreira, julgado insatisfatório pela maior parte dos moradores de Vila União. O que ocorreu, na verdade, foi uma disputa através da qual a Associação de Moradores, apoiada pela Prefeitura, pretendia deslegitimar o Movimento Independente Popular (MIP), que havia organizado grupos de moradores com postura radicalmente contrária à condução das remoções e às inúmeras violações dos direitos humanos sofridos. Devido a essa manobra, a primeira audiência foi avaliada como uma derrota pelos moradores pertencentes ao MIP.

A segunda audiência pública, realizada na Câmara de Vereadores do Rio de Janeiro e organizada pela comissão de direitos humanos desta Câmara, 
revelou-se mais favorável ao grupo contrário às remoções, ajudando-os a articular a estratégia de resistência dos moradores de Vila União, Vila Indiana e Vila Autódromo junto à Defensoria Pública. Após as falas das lideranças populares e da defensoria, os integrantes da comissão de direitos humanos encaminharam relatoria à Câmara, que foi cobrada a acompanhar o desenrolar das remoções nestas três favelas.

No segundo semestre de 2015 o estabelecimento comercial de uma das lideranças do MIP foi demolido após pressão da prefeitura para que deixasse o local. A alegação da prefeitura se baseou no argumento de que o bar se encontrava na rota das obras do BRT. Esta demolição marca o início do enfraquecimento do Movimento Independente Popular, pois o local representava um importante ponto de encontro e debates sobre os problemas da Comunidade. Era realmente um lugar, no sentido dado pelas correntes do pensamento geográfico que valorizam a dimensão afetiva e intersubjetiva do espaço (Tuan,1983). As reuniões passaram a ser realizadas em pontos dispersos da Comunidade sem vínculo histórico com a luta. Desacordos pessoais sobre quais iniciativas tomar geraram uma divisão interna do MIP. Como motivos da divisão, podemos destacar a estratégia de negociação individual feita pela prefeitura para desarticular o movimento e a pressão sofrida pelos moradores, o que fez com que muitos desacreditassem nos resultados positivos da luta. As obras da prefeitura para o BRT da TransOlímpica hoje já adentram a Vila União Curicica.

\section{Considerações Finais}

Buscamos neste trabalho analisar a resistência dos moradores da Vila União Curicica na defesa de seu direito à moradia. Iniciamos com uma análise em escala mais ampliada, por entender que esta violação de um dos direitos humanos básicos faz parte de um processo histórico de acumulação capitalista. No caso das cidades que sediaram megaeventos, a expulsão dos mais pobres, principalmente por obras de infraestrutura foram constantes. África do Sul, Índia e China são exemplos de como somente a roupagem desses eventos foi 
democrática, pois na prática só participaram das decisões o Estado e as grandes empresas (Rolnik, 2014).

No Rio de Janeiro não foi diferente. A Prefeitura da metrópole carioca não poupou esforços para fazer da cidade um lugar convidativo para os investimentos privados, fato que acelerou fortemente o processo de mercantilização do espaço urbano. A Zona Oeste da cidade do Rio de Janeiro é atualmente a principal área de expansão do capital imobiliário, e consequentemente de mudanças nas formas e funções do espaço. Espaços com formas distintas desse ideal de cidade global estão condenadas a desaparecer, como a Vila União em sua configuração original.

Por outro lado, ao modo hegemônico de produção do espaço se contrapõe a organização e luta de movimentos como o sustentado pelos moradores da Vila União Curicica, fortalecido por parlamentares envolvidos com causas populares e democráticas e outros movimentos sociais. A organização tem sido fundamental no sentido de fortalecer os vínculos comunitários e valorizar a história de ocupação do lugar, que se confunde com a história individual de muitos moradores. As diversas reuniões e atos políticos aumentam visivelmente, no morador, o sentido de viver e se reconhecer como próximo dos que vivem situações semelhantes, além de ajudá-lo a ver a si mesmo como agente social implicado nas lutas urbanas. Amplia-se também a consciência da necessidade de se organizar e resistir para ter seus direitos básicos respeitados. Além da importância simbólica, os moradores já vislumbram algumas "vitórias" no difícil contexto em que vivem. A repercussão do caso na imprensa é notável ${ }^{2}$. $\mathrm{Na}$

\footnotetext{
${ }^{2}$ Magalhães, L. (2014, 8 de julho). Para implantar Transolímpico, Rio terá uma das maiores remoções de favelas desde 2009. Jornal O Globo. Disponível em: http://oglobo.globo.com/rio/paraimplantar-transolimpico-rio-tera-uma-das-maiores-remocoes-de-favelas-desde-2009-13271290.

Osborn, C. (2012,14 de dezembro). Vila União de Curicica pode enfrentar remoção total. Rio On Watch. Disponível em: http://rioonwatch.org.br/?p=4491

Matos, T. (2014, 14 de novembro) Moradores da Vila União afirmam que prefeitura descumpriu acordo sobre imóveis. Disponível em: odia.ig.com.br/noticia/rio-de-janeiro/2014-11-14/moradoresda-vila-união-afirmam-que-prefeitura-descumpriu-acordo-sobre-imóveis.html
} 
imprensa e nos dossiês de violações dos direitos humanos, a Vila União Curirica aparece frequentemente.

Os resultados da resistência trouxeram novas ideias nas reuniões dos moradores. Campanhas de arrecadação de alimentos para os mais necessitados, embelezamento e as melhorias dos problemas de infraestrutura do lugar onde vivem são ideias recorrentes nas falas. Apesar de os agentes hegemônicos estarem bem amparados em termos de articulação política e recursos, há muitos exemplos históricos de homens e mulheres que tiveram êxito em defender seus direitos e seus espaços vividos, começando pela questão da moradia. Todo esse processo apresenta uma marca fortemente coletiva, confirmando o pensamento do grande educador brasileiro Freire (1996) de que "ninguém liberta ninguém, ninguém se liberta sozinho: os homens se libertam em comunhão".

Dada a complexidade que encontramos ao estudar o tema em questão, com os seus múltiplos agentes sociais e diversas formas de resistência, é possível entender o espaço urbano carioca contemporâneo como uma arena essencialmente política. A cidade do Rio de Janeiro, é a junção sistêmica de vários recortes espaciais que, em situação de confronto aberto, compõem a metrópole carioca.

A cidade é composta por muitas cidades, mas tal pluralidade, bem como o direito à diferença e de organizar o espaço de acordo com as necessidades e vontades coletivas, é negado por um modelo cujo objetivo primordial é a acumulação. Esse objetivo, na visão dos agentes hegemônicos do espaço, não pode ser "atrapalhado" pela população pobre ou por um movimento social qualquer. Assim, na cidade dominada pelo capitalismo neoliberal, cabe àqueles que ousam viver segundo seus valores atrapalhar os agentes hegemônicos e propor junto à sociedade uma alternativa de cidade. 


\section{Referências Bibliográficas}

Abreu, M. (2011). A evolução urbana do Rio de Janeiro. Rio de Janeiro: IPP Abreu, M. (2014). "A gênese da favela carioca: do campo à cidade, da rejeição ao controle". In: Escritos sobre espaço e história. Rio de Janeiro: Garamond" Ameaçados de Remoção, Moradores de Vila União de Curicica São Informados Que Não Há Moradia Para Todos". Disponível em: <http://rioonwatch.org.br/?p=12892>

"Anúncio de Mudança na Rota do BRT TransOlímpica na Vila União de Curicica: Boa Notícia ou Cavalo de Tróia?" Disponível em: <http://rioonwatch.org.br/?p=13198> Acessado em: 02/12/2014.

Câmara Municipal do Rio de Janeiro. "Projeto de Lei № 807/2010". Disponível em: <http://mail.camara.rj.gov.br/APL/Legislativos/scpro0711.nsf/012cfef1f272c0ec832 566ec0018d831/1eadf96be23c54db83257808007546ae?OpenDocument> Acessado em: 19/09/2014.

COMITÉ POPULAR COPA RIO E OLIMPÍADAS. (2014). "Dossiê Megaeventos e Violações dos Direitos Humanos no Rio de Janeiro". $1^{\text {a }}$ ed. Rio de Janeiro.

"Ilha Pura: Exclusividade, Isolamento e Elitismo na 'Sustentável' Futura Vila Olímpica". Disponível em: <http://rioonwatch.org.br/?p=12658>

Acessado em: 22/08/2014.

Freire, P. (1996). Pedagogia da Autonomia: saberes necessários à prática educativa. São Paulo: Editora Paz e Terra.

Harvey, D. (2003). O novo imperialismo. Tradução Adail Sobral e Maria Stela Gonçalves. São Paulo: Edições Loyola.

Lefebvre, H. (1991). O Direito à Cidade. $1^{a}$ ed. São Paulo: Moraes.

"Mais corte de linhas e o maior número de casas removidas para a instalação de BRTs que já houve (RJ)". Disponível em: https://pelamoradia.wordpress.com/2014/07/28/mais-corte-de-linhas-e-o-maiornumero-de-casas-removidas-para-a-instalacao-de-brts-que-ja-houve/ Acessado em: 13/12/2014.

"Mega-eventos e Reestruturações Urbanas no Rio de Janeiro: a "Paris dos trópicos" e a "cidade olímpica”" São Paulo. S.D. Disponível em:<http://megaeventos.ettern.ippur.ufrj.br/sites/default/files/artigoscientificos/molina_f._mega_eventos_e_reestruturacoes_urbanas_no_rio_de_janeir o_0.pdf> Acessado em: 07/09/2014.

"Pela moradia. 100 Moradores se Reúnem para Resistir às Remoções na Vila União de Curicica (RJ)". Disponível em: https://pelamoradia.wordpress.com/2014/09/19/100-moradores-se-reunem-pararesistir-as-remocoes-na-vila-uniao-de-curicica-rj/ Acessado em: 10/09/2014. 
Pinto, A P. F. "As transformações espaciais na Zona Oeste da cidade do Rio de Janeiro a partir de investimentos infraestruturas e financeiros". Rio de Janeiro. Disponível em: http://www.pucrio.br/pibic/relatorio_resumo2014/relatorios_pdf/ccs/GEO/GEOAntero\%20Vinicius\%20Portela\%20Firmino\%20Pinto.pdf Acessado em: 18/09/2014.

Rolnik, R. (2014). "Megaeventos: direito à moradia em cidades à venda". In: ROLNIK, Raquel; VAINER, Carlos; JENNINGS, Andrew et AL.Brasil em jogo: O que fica da Copa e das Olimpíadas? São Paulo: Boitempo.

Rolnik,R. (org.). Como atuar em projetos que envolvem despejos e remoções? Disponível em: $<$ https://raquelrolnik.files.wordpress.com/2010/01/guia_portugues.pdf Acessado em: 10/01/2015> Santos, M. Espaço e Método. São Paulo: Nobel.

Silva, M. (2003). Percursos, significados e permanência das favelas cariocas (1930-1964). Tese de doutorado. Programa de pós-graduação em geografia, UFRJ, 2003.

Souza e Silva, J. (2002). O espaço em busca do seu lugar: as favelas para além dos estereótipos. In: Território, territórios. PPGEO-UFF, Niterói.

Vainer, C. (2000). Pátria, empresa e mercadoria Notas sobre a estratégia discursiva do Planejamento Estratégico Urbano. in: Vainer, Carlos, Maricato, Ermínia, Arantes, Otília. A cidade do Pensamento Único: desmanchando consensos Vozes: Petrópolis, Rio de Janeiro.

"Vila União de Curicica pede apoio à Comissão de Defesa dos Direitos Humanos da ABl". Disponível em: <http://www.abi.org.br/moradores-de-vila-uniao-decuricica-pedem-apoio-a-comissao-de-defesa-dos-dh-da-abi/> Tuan, Yi-Fu. (1983). Espaço e Lugar: a perspectiva da experiência. São Paulo: Difel.

\section{Para citar este artículo:}

Abreu, A., Reis, B., Couto, M., Seade, R., Damas, T. y Gonçalves, W. (2016). Lutar, resistir! Violações do direito à moradia e resistência popular nas favelas do Rio de Janeiro em tempos de megaeventos. Collectivus, Revista de Ciencias Sociales, 3(2), 129-155. doi: http://dx.doi.org/10.15648/Coll.2.2016.7 